\title{
Estudio de los factores que influyen en estudiantes con tercera matrícula en los periódicos académicos septiembre 2017 - marzo 2018 y abril 2018- agosto 2018 en la Facultad de Ciencias Químicas de la Universidad Central del Ecuador
}

Catota Caiza, Lizbeth Alexandra; Chavarrea Meléndrez, Carol Vanessa; Espinel Armas, Elithsine Elizabeth Estudio de los factores que influyen en estudiantes con tercera matrícula en los periódicos académicos

septiembre 2017 -marzo 2018 y abril 2018- agosto 2018 en la Facultad de Ciencias Químicas de la Universidad Central del Ecuador

Revista Educación, vol. 44, núm. 2, 2020

Universidad de Costa Rica, Costa Rica

Disponible en: http://www.redalyc.org/articulo.oa?id=44062184027

DOl: https://doi.org/10.15517/revedu.v44i2.39068

\section{(c) (1) ब(9)}

Esta obra está bajo una Licencia Creative Commons Atribución-NoComercial-SinDerivar 3.0 Internacional. 


\section{Estudio de los factores que influyen en estudiantes con tercera matrícula en los periódicos académicos septiembre 2017 -marzo 2018 y abril 2018- agosto 2018 en la Facultad de Ciencias Químicas de la Universidad Central del Ecuador}

Analysis of Factors Impacting Students Enrolled in a Course for a Third Time during the September 2017 - March 2018 and April 2018 - August 2018 Academic Periods at the Central University of Ecuador Chemistry Department

Lizbeth Alexandra Catota Caiza

Universidad Central del Ecuador, Ecuador

lacatota2@uce.edu.ec

iD http://orcid.org/0000-0002-1211-0413

Carol Vanessa Chavarrea Meléndrez

Universidad Central del Ecuador, Ecuador

cvchavarrea@uce.edu.ec

(DD http://orcid.org/0000-0003-3368-0404

Elithsine Elizabeth Espinel Armas

Universidad Central del Ecuador, Ecuador

eeespinel@uce.edu.ec

(iD http://orcid.org/0000-0001-5800-7035
DOI: https://doi.org/10.15517/revedu.v44i2.39068

Redalyc: http://www.redalyc.org/articulo.oa?id=44062184027

Recepción: 11 Octubre 2019

Aprobación: 01 Junio 2020

\section{Resumen:}

El presente estudio determinó los factores que influyen para que el estudiantado de la Facultad de Ciencias Químicas, debido a dos reprobaciones, solicite una tercera matrícula. Para ello, se organizó un levantamiento de información de estudiantes, generado en la secretaria de dicha facultad de la Universidad Central del Ecuador; se registra una población de 343 estudiantes que han incidido en una tercera matrícula en los periodos 2017-2018 y 2018-2018, motivo por el cual se analizó las causas o factores que generan un bajo rendimiento estudiantil como los factores sociales, personales, institucionales y pedagógicos que actúan para una tercera matrícula. El estudio obedece al tipo de investigación relacional de carácter transversal y el análisis estadístico se ejecutó por medio de la aplicación del chi-cuadrado. En los resultados obtenidos en lo social, se determinó que los problemas en la familia impiden que el estudiantado pueda dedicarse a tiempo completo, lo cual repercute en un bajo rendimiento, así también los factores académicos como la pedagogía del cuerpo docente y la carga horaria que existe en el sector estudiantil impide que puedan dedicarse a tiempo completo en sus estudios generando un distractor para el desarrollo de conocimiento, finalmente se desarrolló una exploración sobre el origen de las terceras matrículas durante estos periodos, de esta manera se logró conocer que muchos estudiantes se ven afectados por uno o más de estos factores en su aprovechamiento académico, lo cual genera un bajo rendimiento y esto a su vez conlleva a la petición de una tercera matrícula.

Palabras Clave: Factores, Pedagogía, Rendimiento académico, Técnicas de estudio, Tercera matrícula.

\section{Abstract:}

This study seeks to determine factors that influence students in the Chemistry Department to repeat a course for a third time after having failed the course twice (referred to in Ecuador as a third enrollment). A survey to gather student data was conducted by the Office of the Dean for the Chemistry Department at the Central University of Ecuador; Ex343 students registered for the same course a third time during the 2017-2018 and 2018-2018 academic periods. For this reason, the causes leading to low academic performance was analyzed as well as associated social, personal, institutional and pedagogical factors that could lead to a student 's failing a course a second time and, ultimately, a third enrollment. The study methodology is based on cross-sectional relational research with chi-square statistical analysis. Results reflecting social factors revealed that family issues tend to prevent students from concentrating full-time on their studies, thereby leading to low academic performance. Academic factors such as teaching practices of the lecturer or professor combined with taxing workloads are also obstacles that work against a student's academic 
success, and serve as distractors to the full development of their knowledge. Exploratory research was conducted to find the root cause of student third enrollments for these periods. As a result, it was discovered that many of the students are affected by one or more of the aforementioned social and academic factors which hinder their academic achievement causing them to request a third enrollment.

KEYWORDS: Factors, Pedagogical, Academic Performance, Study Techniques, Third Enrollment.

\section{INTRODUCCIÓN}

Esta investigación tiene como objetivo estudiar los factores relacionados con el desempeño académico del alumnado de educación superior de la Facultad de Ciencias Químicas de la Universidad Central del Ecuador, para solicitar a una tercera matrícula, y a su vez, demostrar qué aspectos afectan al estudiantado frente a una tercera matrícula. Se efectuó una exploración de campo a fin de dar respuesta a la pregunta de investigación mediante el análisis de los resultados obtenidos. Por tanto, se partió de una recopilación teórica de trabajos relacionados con este tema, para el estudio y análisis de los diversos factores sociales, personales, pedagógicos e institucionales que influyen en el estudiantado de tercera matrícula de la Facultad de Ciencias Químicas de la Universidad Central del Ecuador. Es por esta razón que los objetivos planteados permitieron llevar a cabo la presente investigación, la cual abarca la problemática acerca de los factores que afectan al sector estudiantil para recurrir a la solicitud de una tercera oportunidad en ciertas asignaturas y poder continuar con sus estudios, por tal razón se llegó a indagar sobre dichos problemas que enfrenta el sector estudiantil. La metodología seguida en la investigación, los resultados estadísticos, su discusión y las conclusiones a las que se llega, permitió concluir con el presente trabajo investigativo.

\section{Antecedentes}

Tejedor y García (2007) investigaron sobre las causas del bajo rendimiento del estudiantado universitario, el criterio del sector docente sostiene que la variable que más influye es el escaso nivel del alumnado sobre conocimientos previos para cursar las asignaturas, seguido de la falta de autocontrol, autoexigencia y responsabilidad de dicho sector, mientras que según el criterio de estudiantes, las principales causas están relacionadas con la dificultad intrínseca de algunas materias y la extensión desproporcionada de los programas, al igual que la falta de autocontrol, responsabilidad y su falta de esfuerzo, es así que se puede interpretar que ambos segmentos educativos deben estar vinculados de manera comprometida para obtener resultados óptimos en cuanto al logro del aprendizaje, caso contrario, el superar la asignatura se torna difícil, llegando inclusive a correr el riesgo de repetirla y de reincidir en la no aprobación, el estudiantado podría optar por solicitar una tercera matrícula en la asignatura pertinente, si la legislación así lo permite.

Al respecto, en la Universidad Industrial de Santander en 2016, se desarrolló un estudio sobre los factores que afectan en el rendimiento académico de estudiantes de enfermería, los cuales desencadenan en reprobación o repitencia de asignaturas, los resultados señalan que la reducción de materias aprobadas se evidenció con mayor recurrencia, durante el primer año de estudios, en un 63,33\% al menos en una asignatura (Cardozo, Tiga, Fajardo y Vargas, 2016), y por tanto, el consiguiente impacto en el ámbito social, económico y educativo; lo anterior, es ratificado por el Ministerio de Educación colombiano, al estudiar la deserción en la educación superior, se estableció que: "ante un aumento de $1 \%$ en la tasa de repitencia, el riesgo de desertar aumenta en 1,47\%" (Universidad de los Andes, 2007, p. 43), evidenciándose mayor deserción en estudiantes de los primeros semestres. Torres, Acevedo y Gallo (2015) se refieren al estudio efectuado por Cortes, Gallego y Rodríguez (2011), sobre un análisis organizado en nueve programas de la Universidad Nacional de Colombia, en el cual determinaron que el 72,35\% del estudiantado que se retiró de los estudios universitarios lo hizo en los primeros cuatro semestres.

En lo referente a la repitencia universitaria, como se ha señalado, es una variable multifactorial, que implican circunstancias personales, sociales, institucionales y pedagógicas, que desembocan en la posibilidad de repetir la asignatura, sin embargo, no siempre se alcanza la promoción de esta, así el estudiantado se ve 
obligado a solicitar una última oportunidad, cuya aprobación o reprobación va anclada a la posibilidad de continuar o no sus estudios en la carrera.

Al desarrollarse estudios sobre factores asociados al rendimiento académico estudiantil, relacionado a la educación superior de la Facultad de Ciencias Químicas de la Universidad Central del Ecuador, se estableció que existen determinantes: personales referidas a la motivación, expectativas, capacidad intelectual, esfuerzo y técnicas de estudio; sociales vinculados a situación social y económica, nivel de educación familiar, entre otros, e institucionales que incluyen al ambiente académico, en el cual se impone una alta exigencia, que finalmente, redunda en la calidad de la educación; sin embargo, los resultados cuantitativos expresados en las calificaciones, pueden contribuir a: promoción o éxito académico, retraso producto de repitencia o abandono de sus estudios por deserción (Garbanzo, 2007).

En el presente estudio se busca establecer los múltiples factores que influyen en el sector estudiantil para solicitar una tercera oportunidad y aprobar asignaturas en las carreras de la Facultad de Ciencias Químicas. En el período 2009-2010 fue de 94 el número de estudiantes a quienes se concedió la tercera matrícula en la Universidad del Azuay, durante el 2011-2012 fueron 105 los casos especiales de esta situación. Carlos Cordero, rector de la Universidad de las Américas (2012) aseveró que "La tercera matrícula es una situación especial que se otorga y que depende de varias circunstancias: el nivel de la carrera en que se encuentra, las notas de matrículas anteriores, las calificaciones durante la carrera y el promedio" (Redacción El Tiempo, 10 de agosto 2012, párr. 5).

\section{MARCo TEÓRICo}

El rendimiento académico, Monzón (2015) lo establece como: "Constructo susceptible de adoptar valores cuantitativos y cualitativos, a través de los cuales existe una aproximación a la evidencia y dimensión del perfil de habilidades, conocimientos, actitudes y valores desarrollados por el alumno en el proceso de enseñanza aprendizaje" (p. 16), es decir, el desempeño estudiantil se lo valora como un elemento resultante de la experiencia educativa, sea de los niveles educativos de: educación primaria, media o universitaria.

Las universidades, como responsables del éxito académico de sus estudiantes en su formación profesional, pueden presentar deficiencias, que se manifiestan como rendimiento académico bajo, así como el abandono de la universidad. Por otro lado, las carreras que ofrece la Facultad de Ciencias Químicas de la Universidad Central del Ecuador demandan de sus estudiantes máxima exigencia, características propias de la profesión. Por lo mismo, requiere de algunos atributos personales como integridad, responsabilidad, madurez, así como condiciones académicas: interés por la profesión, hábitos y técnicas de estudio, asistencia y participación en clase, entre otros (Flores, 2016). Es así que, con estas condiciones, el sector estudiantil de dicha facultad se forma profesionalmente en un proceso de enseñanza aprendizaje que busca su éxito académico, no solo basado en calificaciones, sino en la consecución de un perfil acorde a los requerimientos de la sociedad.

En la Tabla 1, se presenta la totalidad del estudiantado por carreras que conforman la Facultad de Ciencias Químicas en el semestre septiembre 2017-marzo 2018 y en el semestre abril-agosto 2018

TABLA 1

Estudiantes de la Facultad de Ciencias Químicas

\begin{tabular}{|l|l|l|}
\hline Estudiantes de la Facultad de Ciencias Químicas \\
\hline Carrera & $\mathbf{2 0 1 7 - 2 0 1 8}$ & $\mathbf{2 0 1 8}-\mathbf{2 0 1 8}$ \\
\hline Química farmacéutica & 462 & 391 \\
\hline Química de alimentos & 357 & 307 \\
\hline Bioquímica clínica & 390 & 314 \\
\hline Química & 226 & 261 \\
\hline TOTAL & 1435 & 1273 \\
\hline
\end{tabular}


Elaboración propia basada en los datos de la secretaría FCQ.

Los primeros años de estudios universitarios son de gran dificultad para el sector estudiantil, pues implica un desafío la transición de la educación media a la universitaria, la cual conlleva nuevas responsabilidades y organización de tiempo, así como la capacidad de autorregulación y adaptación a las nuevas exigencias académicas. Dichas condiciones podrían afectar en el bajo rendimiento y más aún cuando el alumnado presenta escasos conocimientos para el estudio de las ciencias establecidas, como la capacidad intelectual del alumnado (Pérez, Valenzuela, Díaz, González y Núñez, 2013). Además de la práctica de aprendizaje memorístico, que no permite el desarrollo de capacidades de reflexión crítica, de análisis, de síntesis, argumentación, y aplicaciones en situaciones concretas. El estudiantado con bajo rendimiento académico no logren superar dichas circunstancias, se enfrentan en mayor grado a la desmotivación, ausentismo, repetición y deserción de la universidad; esto último conlleva al riesgo de pérdida de un cupo en el nivel de educación superior.

Diversos estudios refieren a factores que influyen en el bajo rendimiento académico en el sector estudiantil universitario, los cuales pueden generar la pérdida de aprobación en las asignaturas. Entre los factores, que coinciden dichos estudios se tienen los siguientes:

\section{Factores sociales}

Los factores sociales vinculados al fracaso académico son abordados por varias autoras y autores desde distintas perspectivas, estos factores se mencionan en la Tabla 2:

TABLA 2

Dimensiones de los factores sociales

\begin{tabular}{|c|c|}
\hline Factores Sociales & $\begin{array}{l}\text { Ambiente familiar } \\
\text { económica } \\
\text { Estrato social }\end{array}$ \\
\hline
\end{tabular}

Fuente: Elaboración propia de las autoras

\section{Ambiente familiar}

La influencia del padre y la madre responsable de cada estudiante, influye significativamente en la vida académica. Entornos familiares marcados por la violencia familiar han indicado su relación con resultados académicos insuficientes. Datos de este tipo obtenidos en diferentes investigaciones muestran que la presencia de violencia familiar es un factor asociado al fracaso académico (Garbanzo, 2007). Así mismo, ambientes familiares disfuncionales, constituyen un factor de mayor recurrencia en la población ecuatoriana. En este sentido, existe un gran número de estudiantes que tienen problemáticas de orden familiar, lo cual constituye una carga difícil de llevarla, sobre todo, cuando se busca el alcance profesional para mejorar estas condiciones y el contexto familiar no es favorecedor.

\section{Estabilidad económica}

La falta de recursos económicos impide solventar los gastos, lo que genera la necesidad de conseguir trabajo. Los problemas financieros se deben normalmente a la pérdida de empleo o subempleo de quien está a cargo de 
solventar los gastos de las o los estudiantes, en ciertos casos estos son quienes se solventan económicamente. Existen casos evidenciados en que se demuestra que el interés del sector estudiantil hacia su carrera es muy fuerte pese a la dificultad financiera, viéndose abocados a posponer semestres para retomarlos una vez conseguida la financiación que implican sus estudios, o a su vez, tienen que trabajar y estudiar al mismo tiempo.

\section{Estrato social}

El Instituto Nacional de Estadísticas y Censos (INEC) en un estudio determinó que la mayoría de población ecuatoriana se ubica en un estrato medio. La investigación se llevó a cabo con 9744 personas en las ciudades de Quito, Guayaquil, Cuenca, Machala y Ambato, la cual determinó que el 83 \% de la población ecuatoriana se ubican en el estrato medio. Mientras que en el estrato alto alcanza el 1,9\%, y en el estrato bajo el 14,9 \% (INEC, 2011). La mayor parte del sector estudiantil de la Facultad de Ciencias Químicas están dentro del nivel medio y bajo, siendo afectado dicho sector, lo cual implica limitaciones de acceso a mejores condiciones educativas, culturales, calidad de vida, accesibilidad tecnológica, entre otras. Esta condición, se ancla a la anterior, sobre la estabilidad económica, razón por la cual hay jóvenes que no pueden solventar sus requerimientos educativos por ayuda de sus progenitores y deben recurrir a un auto solvento económico. El tener dos responsabilidades en sus manos, también se ha considerado que es un importante factor que llega a influir en la repetición concurrente de una asignatura, debido al corto tiempo que disponen para cada una de ellas. Según estudios el trabajar y estudiar es una carga demasiado estresante.

\section{Factores personales}

Vinculados a la deserción educativa también se encuentran los factores personales los cuales son vistos en diferentes perspectivas a criterio del sector investigador, como se observa en la Tabla 3:

TABLA 3

Dimensiones de los factores personales

\begin{tabular}{|c|c|}
\hline Factores personales & $\begin{array}{l}\text { Jornadas extensas } \\
\text { Retroalimentación de } \\
\text { información } \\
\text { Organización de tiempo. } \\
\text { Carencia de hábitos } \\
\text { Técnicas de estudio. } \\
\text { Aprendizaje autónomo. } \\
\text { Salud integral } \quad \text { Perfil } \\
\text { vocacional } \quad \text { Estado civil }\end{array}$ \\
\hline
\end{tabular}

Fuente: Elaboración propia de las autoras.

\section{Jornadas extensas}

La amplia jornada de estudio tiene un impacto negativo en el área académica, ya que al tener un alto número de materias el estudiantado puede presentar un bajo rendimiento académico, pues es una variable significativa entre las variables académicas que influyen en el rendimiento académico de jóvenes de educación superior. 
Al respecto se menciona según Fernadez (2011): "Las horasde trabajo tuvieron un impacto negativo en el desempeño de los alumnos" (p. 175), dado que ello impide una mejor concentración al tener una carga horaria alta. Es por esta razón que se debe cumplir un número adecuado de horas semanales por asignaturas, según la planificación curricular. Sin embargo, en las carreras de la facultad, la irregularidad académica que se genera por repotencia de asignaturas, provoca que el estudiantado deba tomar asignaturas del siguiente semestre y las que repite, lo cual implica alta carga académica, debido a la ansiedad estudiantil de tomar más asignaturas para evitar el retraso.

\section{Retroalimentación de información}

Los procesos académicos requieren no solo de planificación adecuada sino de una efectiva metodología y pertinente evaluación de los contenidos de las asignaturas. Esto último implica generar procesos de retroalimentación de alcances y resultados para lograr la apropiación de la información; sin embargo, la excesiva cantidad del alumnado en clase, impide controlar la calidad de la educación, generando una experiencia de aprendizaje poco ameno y una educación menos personalizada, lo que genera muy poca retención de información por parte del sector discente.

\section{Organización del tiempo}

El diseño educativo para evitar reproducir modelos didácticos poco eficientes, es considerar el tiempo que el estudiantado requiere para estudiar y ejecutar las actividades académicas, flexibilizar las opciones de tareas por desarrolar, los tiempos destinados a estas y las formas de comunicación (Bañuelos, Guerrero y Sánchez, 2013). Es decir, se requiere el fortalecimiento en el alumnado de técnicas de estudio que permita distribuir correctamente el tiempo empleado en todas sus actividades, de esta manera se puede lograr un aprendizaje autónomo y eficiente.

\section{Técnicas de estudio}

John Dunlosky (2018), profesor de Psicología de la Universidad de Kent, asegura: "Me sorprende que alguna de las estrategias de estudio que más emplean los estudiantes ofrezcan beneficios mínimos en su aprendizaje" (párr.3). Esta descripción dirige valorar la adopción de determinada técnica de estudio adecuada para procesar la información y, de esta manera alcanzar mejores conocimientos con el consiguiente mejoramiento en el rendimiento académico para disminuir en índice de repitencia. Sin embargo, la carencia de hábitos es una realidad en el estudiantado, lo cual repercute de manera directa en el alcance de sus resultados de aprendizaje.

\section{Aprendizaje autónomo y carencia de hábitos}

Promover el aprendizaje autónomo en el estudiantado es una de las prioridades en las instituciones educativas de nivel medio superior y superior como se mencionó en un estudio efectuado sobre el desarrollo de aprendizaje autónomo a partir de la identificación de los estilos de aprendizaje por la Universidad Autónoma del Estado de Hidalgo, desarrollado por Machorro y Valdez (2016), sin embargo, en el artículo mencionado se consideró que los estilos de apropiación como un hábito de estudio preferentes del alumnado, son las estrategias de aprendizaje y de enseñanza están relacionadas a la capacidad de aprender por el alumnado, sin necesidad de alguien más. 


\section{Salud integral}

Los estados de ánimo influyen mucho en la tensión y la capacidad de trabajo porque de eso depende el autoestima y estado psicológico del estudiantado, por ende, el bajo rendimiento escolar no es solo una mala calificación, pues no se trata de reprobar una o dos clases. El estudiantado puede sentirse agobiado cuando deben repetir muchas veces la materia reprobada. Junto a la tremenda carga de trabajo acumulado, el alumnado se estresa, y la motivación se reduce por muchos factores adicionales:

Sienten que no se la pueden con el trabajo que se les viene.

Gastos económicos

Lamentan que sus compañeras o compañeros avancen por delante de ellos.

Sienten que, aunque les gusta la carrera, la carrera no está hecha acorde a su personalidad.

Falta de interacción de calidad con el grupo de docentes.

Estudios relacionados a los factores que inciden en el rendimiento académico en el estudiantado universitario, desde la calidad de la educación superior pública, señalan una relación importante entre bienestar psicológico y rendimiento académico. Lo mismo sucede con las creencias de eficacia académica y las relaciones entre éxito académico. (Garbanzo, 2007). Es decir, existe una relación directa entre el aprovechamiento y la salud integral tanto física como psicológica del alumnado.

\section{Perfil vocacional}

En los últimos años, el acceso al sistema de educación superior está anclado a la calificación obtenida en el examen de ingreso, sin considerar el perfil vocacional, aptitudes e intereses del estudiantado, ocasionando en reiteradas ocasiones que el ingreso a las carreras de la Facultad no era una de sus primeras opciones elegidas, o su ingreso es transitorio, para poder pedir cambio de carrera una vez admitido como estudiante y aprobado los dos primeros semestres. Este panorama no está siendo atendido de manera efectiva, pues las universidades siguen recibiendo a un sinnúmero de estudiantes que desconocen su vocación y por ende a la carrera que ingresan. Gran parte del alumnado abandona sus estudios en los primeros semestres (alrededor de un $60 \%$ del total de desertores), especialmente por causas académicas y de orientación profesional y vocacional, como menciona (Quica, 2016).

\section{Estado civil}

Otro factor muy ligado al anterior es el estado civil. Cierto número de estudiantes tienen responsabilidades familiares como padres o madres, es decir, tienen familia que depende de su persona, carecen de apoyo familiar y el trabajo les impide dedicar tiempo suficiente a los estudios, además que un entorno estresante provoca problemas familiares. Estos contratiempos tienden a desvincular los objetivos de superación por los problemas que se presenta. Con relación al perfil del alumnado que cursa el sistema abierto en la Facultad de Psicología de la Universidad Nacional Autónomo de México en efecto, el perfil del estudiantado del sistema abierto ha cambiado no solo en sus características socioeconómicas, edad y estado civil, sino también en cuanto a su motivación, expectativas y horizonte laboral. (Bañuelos et al., 2013).

\section{Factores Institucionales}

Otros factores que impiden el desarrollo del conocimiento académico son los instituciones (Tabla 4): 
TABLA 4

Dimensiones de los factores institucionales

\begin{tabular}{|l|l|}
\hline Factores & \multicolumn{1}{c|}{ Sistema de evaluación } \\
institucionales & Responsabilidad que \\
& exige los niveles Superiores \\
& Organización \\
& institucional \\
& Preparación docente \\
& Infraestructura \\
\hline
\end{tabular}

Fuente: Elaboración propia de las autoras

\section{Sistema de evaluación}

Las universidades muchas veces desconocen el nivel de conocimiento previo con el que el estudiantado bachiller cuenta para ingresar a la universidad, por la cual institutos particulares comparten cursos con el fin de nivelar los conocimientos de todo el alumnado.

El paso de la enseñanza media a la enseñanza universitaria puede significar una vida nueva en otro lugar, alejarse de la familia, asistir a clases y distribuir tiempo y recursos materiales en forma eficiente. (Pérez et al., 2013). En el cambio del colegio a la universidad existe diferencia en distintos aspectos, sobre todo en el nivel de exigencia:

- La universidad carece de control para asistir a clases y tener los apuntes al día, en cambio en los colegios exige el reglamento institucional la asistencia obligatoria del estudiantado.

- En la universidad el resultado del proceso de estudio es de mayor grado de exigencia y con predominancia del aprendizaje autónomo, así como con menor contacto personal docenteestudiante, lo que puede afectar la motivación por el estudio .

\section{Responsabilidad que exige los niveles superiores}

Si bien es cierto que, la capacidad de apropiarse del conocimiento por cada estudiante es diferente, hay asignaturas por niveles que requieren de mayor concentración y exigencia por parte de este. No se puede dejar de lado, el papel que juega la inteligencia de cada individuo, pues cada persona tiene diferente formación de estudio, pero también existe otra serie de factores como el razonamiento verbal, espacial, numérico, abstracto, etc., que determinan habilidades que dotan a las personas la facilidad para afrontar cierto tipo de tareas y el conocerlas evitará abandonar los estudios, pues le posibilitará tener una mejor participación y efectividad en el proceso de enseñanza aprendizaje (PEA).

\section{Organización institucional}

Esto está relacionado con los escasos recursos y defectos de organización, superpoblación universitaria, deficiencias docentes, falta de ayuda organizada para estudiantes, currículos inadecuados y carencia de información (Quica, 2016). Una mala organización curricular es otra de las causas que repercute al alumnado debido al contenido de la malla y esta mala organización puede darse debido a la falta de experiencia por parte del personal docente al no disponer de adecuado material académico y esto junto con la falta de metodología puede ser un causante para no lograr un aprendizaje eficiente, lo que aumenta los índices de deserción y repitencia. 


\section{Preparación docente}

La formación íntegra es uno de los aspectos esenciales para el perfeccionamiento profesional del cuerpo docente universitario y es básica para lograr no solo universidades de calidad y excelencia, sino también estudiantes con conocimientos sólidos (Montes y Suárez, 2016). Por esta razón, quienes ejercen la docencia deben ser un sector entendido no solo de la materia que imparte, sino que también debe dominar contenidos teóricos y metodológicos de la psicología y la pedagogía, que le posibiliten mejorar el desarrollo de la personalidad del alumnado. Es por esta razón que, para que el cuerpo docente pueda mejorar su formación como tal, es importante la disposición de su tiempo para tomar cursos y seminarios constantes que cubran las necesidades como profesionales docentes y les ayuden a perfilar su competencia pedagógica.

\section{Infraestructura}

La enseñanza teórica va de la mano con la enseñanza práctica, la cual se lleva a cabo en los laboratorios, con el fin de reforzar la teoría en aquellas asignaturas que se lo requiere. Por tanto, estos laboratorios deben contar con todos los elementos necesarios para desarrollar un buen aprendizaje. Así mismo, debido a las largas jornadas de permanencia en la institución, las instalaciones deben contar con una infraestructura adecuada y suficiente, así como mecanismos de mantenimiento permanente, de manera que se posibilite un ambiente sano, agradable y ameno. La gestión administrativa o el mejoramiento de la infraestructura escolar, tiende a orientarse hacia la elaboración de reglamentos, que más que fomentar un buen ambiente estudiantil o una identidad compartida al interior de la institución escolar, tratan de mejorar el contexto de trabajo. (Poblete, Sepúlveda, Orellana y Abarca, 2013).

\section{Factores pedagógicos}

Otro de los factores que influyen en el éxito académico son los pedagógicos, estos son analizados por grupos de investigación que se visualizan en la Tabla 5:

TABLA 5

Dimensiones de los factores pedagógicos

\begin{tabular}{|l|l|}
\hline Factores pedagógicos & \multicolumn{1}{|c|}{ Estrategias didácticas } \\
& \multicolumn{1}{|c|}{ Aprendizaje } \\
& Tutorías . \\
& $\begin{array}{l}\text { Carga horaria . Relación } \\
\text { alumnado-profesorado . } \\
\text { Perfil profesional del grupo docente }\end{array}$ \\
\hline
\end{tabular}

Fuente: Elaboración propia de las autoras

\section{Estrategias didácticas}

Las estrategias didácticas correctamente diseñadas y utilizadas por parte del sector docente en el aula, permiten una mejor comprensión de los contenidos a estudiar y con ello hacer eficiente el proceso de enseñanza-aprendizaje. (Corral y Díaz, 2009), lo que provocará en el sector estudiantil que retenga con mayor facilidad el contenido académico mejorando así su memoria a largo plazo y logrando un conocimiento eficiente. 


\section{Aprendizaje eficiente}

En el artículo de Jiménez, (2014), titulado Lo que necesita un buen estudiante, de manera general indica que el alumnado hoy en día es parte central de la enseñanza-aprendizaje, a través del tiempo se ha ido modificando la educación con el objetivo de lograr mejores resultados en el rendimiento académico. Si se hace un breve recuento de cómo era la educación hace algunos años, el cuerpo docente era el que debía exponer los temas y brindar la información, materiales y actividades al alumnado. Hoy en día el estudiantado debe investigar para que sean quienes presenten los temas e intercambien información con sus compañeras y compañeros enriqueciendo sus conocimientos y obteniendo un aprendizaje eficiente. En el artículo sobre: Lo que necesita un buen estudiante, su autora hace referencia a que el estudiantado debe obtener sus conocimientos a través de la indagación, usando la reflexión, aprendiendo a ser crítico, que investigue y que, por supuesto proponga, con el fin de llegar a un aprendizaje eficiente y con ellos apreciar la experiencia adquirida para el gran paso hacia el cambio que se espera en el ámbito del conocimiento del alumnado.

\section{Tutoría}

El fin de un aprendizaje eficiente consiste en la gestión en las iniciativas estudiantiles y docentes frente a problemáticas sociales desde recursos didácticos y económicos que brinden las posibilidades de desarrollo humano, económico, tecnocientífico, cultural, en pro de calidad de vida y bienestar (Zárate y Mantilla, 2014). En ocasiones las clases de refuerzo o Tutoría son necesarias para aclarar parte de la información que no logró ser retenida, de esta manera se busca dar otras opciones, fuera del aula, para lograr mejores resultados en el estudiantado que presenta mayor dificultad en comprender la asignatura.

\section{Carga horaria}

El complejo horario de clases del estudiantado universitario es una de las principales razones de que el alumnado se aburra y esto genere a su vez la pérdida de la asignatura, pues la materia presenta una carga de horario excesiva y provoca en ellos un déficit de atención, lo cual limita el aprendizaje y desenvolvimiento frente a la acumulación de trabajos lo que da como resultado que el alumnado demuestre desinterés de la materia y provoque nuevamente otra matrícula. Sin embargo, la dinamización en el aula, mediante la recursividad docente, puede conllevar a que el estudiantado se mantenga atento y disfrute de la experiencia de aprendizaje, pues una clase larga puede ser superada por un tratamiento interesante de los temas.

\section{Relación alumnado - profesorado}

Un alto índice de estudiantes que desertan y aluden me fui porque me aburrí, pero eso no es todo, pues hay algo más importante detrás de esa falta de compromiso estudiantil como el trato, problemas con el profesorado y la escuela, motivación innata y falta de apoyo estudiantil por parte de familiares y autoridades.

Las expectativas que el alumnado tiene sobre las relaciones con el grupo docente y el estudiantado son factores importantes que intervienen en los resultados académicos, los cuales hacen referencia a que el estudiantado desean encontrar en el profesorado tanto una relación afectiva, como didáctica, ya que ello tiene repercusiones en el rendimiento académico (Garbanzo, 2007). Así aquellas barreras que enfrenta el estudiantado en las carreras universitarias es lo que conlleva a deserción. 


\section{Perfil vocacional del grupo docente}

Muchos expertos en educación, según Flores (2016) coinciden que la experiencia de aprendizaje mejora si la preparación del cuerpo docente y facultades trabajaran de manera más didáctica con el estudiantado, es sumamente crítico de esa falta de conciencia y señala que las universidades para un correcto funcionamiento deben contratar profesoras y profesores que de cierta manera sean guías para el alumnado y estos a su vez puedan obtener un aprendizaje de calidad. Cabe señalar que al hablar de la pedagogía de cuerpo docente es fundamental la paciencia y tolerancia que deben poseer frente a sus estudiantes.

\section{Marco normativo: Reglamento de las terceras matrículas de la Universidad Central del Ecuador}

Art. 1. El estudiante tiene derecho a tercera matrícula, en una misma asignatura, solamente en casos establecidos excepcionalmente en el estatuto de la institución, y lo hará en el siguiente ciclo o semestre de aprobada la solicitud.

Art. 4. La excepcionalidad contempla los siguientes casos

a) Calamidad doméstica debidamente fundamentada.

b) Enfermedad debidamente comprobada con certificado médico otorgado por el Hospital del Día, Hospital del IESS o Ministerio de Salud.

c) Maternidad.

d) Problemas académicos y administrativos no imputables al estudiante.

e) Cuando el requirente demuestre haber aprobado el $60 \%$ o más de la malla curricular de su carrera y no haya registrado otra tercera matrícula en su historial académico. Esta excepcionalidad será concedida por una sola vez y en una sola asignatura.

Art. 5. El estudiante de una carrera que utilizó tercera matrícula en una misma asignatura reprobándola, puede cambiarse por una sola vez a otra Carrera de la misma Facultad u otra Unidad Académica de la Universidad, en cuyo pensum de estudios no contemple ninguna asignatura con los mismos contenidos.

Art. 6. Si el estudiante viene de otra Universidad o es reingresante, se sujeta a las mismas disposiciones previstas en el Art. 5 de este Reglamento.

Art. 7. El estudiante que hace uso de tercera matrícula puede matricularse en las materias que no tienen como requisito la/s asignatura /as de tercera matrícula.

Art. 8. En la tercera matrícula de la materia o materias no existirá opción a examen de gracia o de mejoramiento. "El examen de gracia o mejoramiento, corresponde al examen supletorio" (H.C.U. sesión 8-II-2011).

Art. 9. La primera y segunda matrícula, son susceptibles de anulación solo hasta después de treinta días de iniciado el ciclo, curso o nivel académico, luego de este plazo se asumirá como cursada aun cuando el estudiante no tenga registradas calificaciones y asistencias en la Secretaría de la Carrera.

Art. 10. El estudiante pueda solicitar, por una sola vez, la anulación de la tercera matrícula, previa la certificación de la Secretaría de la Facultad de no haber registrado calificaciones y asistencia durante el período académico, semestre o año lectivo en curso, finalizado el cual no podrá solicitar dicha anulación. (Universidad Central del Ecuador, 2018, pp.2-3)

\section{Requisitos para terceras matrículas}

Según indicaciones dadas por la Dirección de Tecnologías de la Información, ya NO es necesario receptar en las carreras las solicitudes y el justificativo para tomar asignaturas con tercera matrícula en físico, porque la solicitud la genera el alumnado y sube los justificados de acuerdo a la causal definida, en conformidad al Reglamento de Terceras Matrículas, a través del proceso implementado en el Sistema Académico Universitario SIIU.

Solicitar autorización tercera matrícula

La información por registrar en sistema académico

El sistema verificará la solicitud para poder ser aceptado o denegado al estudiante 
El documento que se puede adjuntar a la solicitud deberá contener un tamaño no mayor a 1Megabyte. (Universidad Central del Ecuador, 2018, p.1) Ver Anexo 1.

\section{Metodología}

La presente investigación estuvo sujeta al paradigma cuantitativo debido a la descripción de los factores que influyen en el desempeño académico. El nivel de investigación de tipo relacional ya que este modelo se apoyó en la asociación de Chi cuadrado evaluando la incidencia de los diferentes factores que incurren en el estudiantado perteneciente a la Facultad de Ciencias Químicas de la Universidad Central del Ecuador, además es un estudio transversal, el cual permitió medir el índice de factores que afectan a estudiantes que requieren efectuar una tercera matrícula provocada por doble repitencia de una asignatura. El estudio reunió los requisitos para desarrollar una investigación bibliográfica de campo, puesto que se desea conocer las condiciones que incrementan la probabilidad en la que uno de estos factores sociales, personales, institucionales y pedagógicos pueda reincidir en una tercera matrícula en el estudiantado de la Facultad de Ciencias Químicas.

Con base en los listados proporcionados por la secretaría de la Facultad de Ciencias Químicas del estudiantado que ha solicitado por una tercera matrícula durante los periodos señalados se determinó una población de 343 estudiantes que corresponde a una muestra calculada de 126 estudiantes de tercera matrícula la cual fue tomada la encuesta para siguiente estudio. Se escogió el muestreo aleatorio simple por medio del diseño de bloques, que es la técnica del muestreo probabilístico en la que todos los elementos que forman el universo que comprende el estudiantado que solicitó tercera matrícula en la Facultad de Ciencias Químicas y tienen la misma probabilidad de ser seleccionados para la muestra, porque todos se muestran en las mismas condiciones (Sampieri, Hernández, Baptista, y Pérez, 1991).

\section{Técnicas e instrumentos de recolección de datos}

\section{Técnica: Encuesta}

Para esta investigación se utilizó la técnica de la encuesta, la cual permitió recoger datos sin modificar el entorno ni el fenómeno donde se genera la información ya sea para entregarlo en forma de tríptico, gráfica o tabla. Los datos se los obtuvo al organizar un conjunto de preguntas normalizadas dirigidas a una muestra representativa o al conjunto total de la población estadística en estudio, integrada a menudo por estudiantes con el fin de conocer estados de opinión, ideas, características o hechos específicos (Sampieri et al., 1991). En este caso la muestra estuvo compuesta por el alumnado de la Facultad de Ciencias Químicas y se estudiaron los elementos multifactoriales que influyen en la solicitud de terceras matrículas.

Se evaluó la precisión de la encuesta mediante la ejecución de un análisis de fiabilidad. Dicha encuesta se aplicó a 126 estudiantes de la Facultad de Ciencias Químicas de la Universidad Central del Ecuador que apelaron una tercera matrícula durante los periodos 2017-2018 y 2018-2018 con el propósito de analizar los diferentes factores socioeconómicos que influyen en el alumnado para la apelación a una tercera matrícula. Esta encuesta estuvo integrada de 23 preguntas cerradas (dos opciones), es decir, no da lugar a respuestas en forma de opiniones, ni otras opciones a parte de las propuestas en cada pregunta.

\section{Diseño: Diseño de bloques completamente al azar}

Este diseño se utilizó ya que este estudio nos permite conocer si los factores influyen o no en el rendimiento académico por parte del estudiantado de la Facultad de Ciencias Químicas, donde este diseño nos 
proporciona la aleatorización de los tratamientos dentro de los bloques y así poder elegir el factor que este puede ejercer sobre dicha temática, es decir, sobre el bajo redimiendo académico que la población presenta.

\section{Instrumento: Cuestionario}

Al desarrollar esta investigación se utilizó el cuestionario, siendo este un documento formado por un conjunto de preguntas redactadas de forma coherente y organizadas, secuenciadas y estructuradas de acuerdo con una determinada planificación, con el fin de que las respuestas puedan ofrecer toda la información. (Sampieri et al., 1991). Se utilizó este instrumento de recolección de datos por la facilidad con la que se llega al estudiantado encuestado no requiere incurrir en gastos económicos elevados por este y tienen respuestas estandarizadas que hacen más simple la tabulación de los datos.

Se determinó la confiabilidad de los resultados obtenidos, tras aplicar el instrumento de recolección de datos, se utilizó el método alfa de Cronbach, pues en esta investigación se aprovechó una encuesta con preguntas politómicas y mediante este coeficiente, que permitió estimar la fiabilidad del instrumento de medida a través de un conjunto de ítems que se espera que midan el mismo constructo o dimensión teórica (Sampieri et al., 1991), se determinó la confiabilidad de la encuesta aplicada. Cuanto más cerca se encuentre el valor del alfa a 1 mayor es la consistencia interna de los ítems analizados. La fiabilidad de la escala debe obtenerse siempre con los datos de cada muestra para garantizar la medida fiable del constructo en la muestra concreta de investigación (Sampieri et al., 1991). En esta investigación el resultado del Alfa de Cronbach fue de 0,7 lo que permitió aplicar la encuesta a la población total.

Como primer punto se planteó determinar los factores sociales, personales, institucionales y pedagógicos a los que está expuesto el estudiantado que apela una tercera matrícula de la Facultad de Ciencias Químicas, para ello se procedió a la utilización de la técnica de encuesta, cuyo instrumento de recolección de datos es el cuestionario, además se pretendió determinar la manera en la que estos factores influyen en el estudiantado para un bajo rendimiento académico, lo que genera un índice de repitencia.

\section{Dimensiones de los factores sociales}

En la Tabla 6 se muestra la probabilidad de algunos ítems de los factores sociales que influyen a la apelación de una tercera matrícula.

TABLA 6

Dimensiones de los factores sociales

\begin{tabular}{|l|l|l|}
\hline Dimensiones & Deseado & Esperado \\
\hline \multirow{5}{*}{$\begin{array}{l}\text { Factores } \\
\text { Sociales }\end{array}$} & $\begin{array}{l}\text { Ambiente } \\
\text { familiar }\end{array}$ & $\begin{array}{l}\text { Los problemas familiares representan una } \\
\text { distracción en el desempeño escolar. La } \\
\text { falta de apoyo en general que carece el } \\
\text { alumnado durante sus estudios puede ser } \\
\text { perjudicial en cuanto al bienestar } \\
\text { psicológico. }\end{array}$ \\
\cline { 2 - 3 } & $\begin{array}{l}1.2 . \\
\text { Estabilidad }\end{array}$ & $\begin{array}{l}\text { Los gastos universitarios son provistos por } \\
\text { los progenitores del estudiantado y un } \\
\text { escaso porcentaje indican solventar sus } \\
\text { necesidades de forma autónoma. }\end{array}$ \\
\cline { 2 - 3 } & $\begin{array}{l}\text { económica } \\
\text { Estrato } \\
\text { social }\end{array}$ & $\begin{array}{l}\text { Debido a las escasas posibilidades } \\
\text { económicas el alumnado se ve obligado a } \\
\text { dividir su tiempo entre el estudio y el } \\
\text { trabajo, lo que genera una incomodidad } \\
\text { tanto académica como laboral }\end{array}$ \\
\hline
\end{tabular}




\section{Dimensiones de los factores personales}

La Tabla 7 presenta la probabilidad de algunos ítems de los factores personales que influyen a la apelación de una tercera matrícula.

TABLA 7

Dimensiones de los factores personales

\begin{tabular}{|c|c|c|}
\hline Dimensiones & Deseado & Esperado \\
\hline \multirow[t]{9}{*}{$\begin{array}{l}\text { Factores } \\
\text { Personales } \\
\text { Factores } \\
\text { personales }\end{array}$} & $\begin{array}{l}\text { 2.1. Jornadas } \\
\text { extensas }\end{array}$ & $\begin{array}{l}\text { La planificación académica influye } \\
\text { en el alumnado en un tiempo } \\
\text { insuficiente para lograr un } \\
\text { beneficio académico. }\end{array}$ \\
\hline & $\begin{array}{l}2.2 . \\
\text { Retroalimentación } \\
\text { de información }\end{array}$ & $\begin{array}{l}\text { El exceso de tareas impide } \\
\text { distribuir el tiempo para lograr el } \\
\text { aprendizaje, ya que debido a la } \\
\text { carga horaria de otras asignaturas } \\
\text { el tiempo de estudio se reduce. }\end{array}$ \\
\hline & $\begin{array}{l}2.3 . \\
\text { Organización de } \\
\text { tiempo }\end{array}$ & $\begin{array}{l}\text { Las horas empleadas para el } \\
\text { aprendizaje no son las suficientes } \\
\text { según las horas de clase razón por } \\
\text { la cual se exige una preparación } \\
\text { autónoma para afianzar los } \\
\text { conocimientos. }\end{array}$ \\
\hline & $\begin{array}{l}\text { 2.4. Carencia de } \\
\text { hábitos }\end{array}$ & $\begin{array}{l}\text { La falta de hábitos de estudios } \\
\text { influye en el desenvolvimiento } \\
\text { académico, puesto que estos } \\
\text { forman parte del éxito del sector } \\
\text { estudiantil. }\end{array}$ \\
\hline & $\begin{array}{l}\text { 2.5. Técnicas de } \\
\text { estudio }\end{array}$ & $\begin{array}{l}\text { Según la encuesta el y la docente } \\
\text { debe llegar a la formación del } \\
\text { estudiantado con una metodología } \\
\text { adecuada y esencialmente } \\
\text { estructurada. }\end{array}$ \\
\hline & $\begin{array}{l}\text { 2.6. Aprendizaje } \\
\text { autónomo }\end{array}$ & $\begin{array}{l}\text { El aprendizaje memorístico no es } \\
\text { estable, razón por la cual impide } \\
\text { un aprendizaje adecuado. Con } \\
\text { base en las encuestas, se puede } \\
\text { apreciar que existe una } \\
\text { preocupación por el aprendizaje } \\
\text { autónomo. }\end{array}$ \\
\hline & $\begin{array}{l}\text { 2.7. Salud } \\
\text { integral }\end{array}$ & $\begin{array}{l}\text { Los inconvenientes que se } \\
\text { presentan en el estudiantado } \\
\text { impiden un correcto } \\
\text { desenvolvimiento en las } \\
\text { asignaturas. }\end{array}$ \\
\hline & $\begin{array}{l}\text { 2.8. Perfil } \\
\text { vocacional }\end{array}$ & $\begin{array}{l}\text { Existe un leve porcentaje de } \\
\text { estudiantes que manifiesta la } \\
\text { inconformidad al respecto de su } \\
\text { carrera. }\end{array}$ \\
\hline & 2.9. Estado civil & $\begin{array}{l}\text { El rol de padre o madre que llegan } \\
\text { a cumplir el estudiantado influye y } \\
\text { genera un malestar emocional } \\
\text { debido a la carga de } \\
\text { responsabilidades, lo que influye } \\
\text { en el desempeño académico. }\end{array}$ \\
\hline
\end{tabular}

Fuente: Elaboración propia con base en la Matriz de Operacionalización de Variables. 


\section{Dimensiones de los factores institucionales}

La Tabla 8 muestra la probabilidad de algunos ítems de los factores institucionales que influyen a la apelación de una tercera matrícula.

TABLA 8

Dimensiones de los factores institucionales

\begin{tabular}{|c|l|l|}
\hline Dimensiones & Deseado & Esperado \\
\hline $\begin{array}{l}\text { res } \\
\text { institucionales }\end{array}$ & $\begin{array}{l}\text { 3.1. Sistema de } \\
\text { evaluación }\end{array}$ & $\begin{array}{l}\text { La planificación del cuerpo } \\
\text { docente ha influido en el } \\
\text { desempeño académico del } \\
\text { estudiantado de forma } \\
\text { cuantitativa, por ende, cualitativa. }\end{array}$ \\
\cline { 2 - 3 } & $\begin{array}{l}3.2 . \\
\text { Responsabilidad } \\
\text { que exige los } \\
\text { niveles superiores }\end{array}$ & $\begin{array}{l}\text { La responsabilidad académica es } \\
\text { mayor en niveles superiores, ya } \\
\text { que exige un poco más porque se } \\
\text { enfoca en el área profesional. }\end{array}$ \\
\cline { 2 - 3 } & $\begin{array}{l}\text { 3.3. Preparación } \\
\text { docente }\end{array}$ & $\begin{array}{l}\text { La preparación del grupo docente } \\
\text { es parte fundamental para el } \\
\text { proceso de aprendizaje del } \\
\text { estudiantado. }\end{array}$ \\
\cline { 2 - 3 } & $\begin{array}{l}\text { 3.4. Organización } \\
\text { institucional }\end{array}$ & $\begin{array}{l}\text { La falta de planificación por parte } \\
\text { de las autoridades interviene en el } \\
\text { desarrollo académico. }\end{array}$ \\
\cline { 2 - 3 } & $\begin{array}{l}\text { 3.5. } \\
\text { Infraestructura }\end{array}$ & $\begin{array}{l}\text { La infraestructura académica } \\
\text { influye en el desenvolvimiento } \\
\text { del estudiantado, pues esto } \\
\text { genera un ambiente adecuado. }\end{array}$ \\
\hline
\end{tabular}

Fuente: Elaboración propia con base en la Matriz de Operacionalización de Variables.

\section{Dimensiones de los factores pedagógicos}

La Tabla 9 detalla la probabilidad de algunos ítems de los factores pedagógicos que influyen a la apelación de una tercera matrícula. 
TABLA 9

Dimensiones de los factores pedagógicos

\begin{tabular}{|c|c|c|}
\hline Dimensiones & Deseado & Esperado \\
\hline \multirow{6}{*}{$\begin{array}{c}\text { Factores } \\
\text { pedagógicos }\end{array}$} & \begin{tabular}{|l|}
4.1. \\
Estrategias \\
didácticas
\end{tabular} & $\begin{array}{l}\text { La pedagogía del sector docente ha } \\
\text { facilitado el proceso de enseñanza - } \\
\text { aprendizaje del alumnado. }\end{array}$ \\
\hline & \begin{tabular}{|l|}
4.2. \\
Aprendizaje \\
eficiente
\end{tabular} & $\begin{array}{l}\text { Según las encuestas efectuadas, para } \\
\text { un aprendizaje eficiente se debe } \\
\text { emplear técnicas de estudio para } \\
\text { fomentar un ambiente motivante. }\end{array}$ \\
\hline & 4.3. Tutorias & $\begin{array}{l}\text { La diferencia entre ambos resultados } \\
\text { es minima, razón por la cual se } \\
\text { entiende que no muchas de las veces } \\
\text { las tutorias son beneficiosas para } \\
\text { aclarar dudas. }\end{array}$ \\
\hline & $\begin{array}{l}\text { 4.4. Carga } \\
\text { horaria }\end{array}$ & $\begin{array}{l}\text { La carga horaria impide que el } \\
\text { estudiantado preste la atención } \\
\text { Suficiente a la asignatura tomada por } \\
\text { la extensa jornada de actividades } \\
\text { académicas. }\end{array}$ \\
\hline & $\begin{array}{l}\text { 4.5. Relación } \\
\text { alumnado - } \\
\text { profesorado }\end{array}$ & $\begin{array}{l}\text { El ambiente de comunicación no } \\
\text { permite una correcta interacción entre } \\
\text { docente y estudiante. }\end{array}$ \\
\hline & $\begin{array}{l}\text { 4.6. Perfil } \\
\text { profesional } \\
\text { del grupo } \\
\text { docente }\end{array}$ & $\begin{array}{l}\text { El perfil del grupo docente debe } \\
\text { contar con la capacidad de } \\
\text { interactuar, liderar un grupo y sobre } \\
\text { todo comunicar de manera didáctica } \\
\text { al estudiantado durante el proceso } \\
\text { educativo, es decir la metodología } \\
\text { empleada. }\end{array}$ \\
\hline
\end{tabular}

Fuente: Elaboración propia con base en la Matriz de Operacionalización de Variables.

Fuente: Elaboración propia con base en la Matriz de Operacionalización de Variables.

\section{Resultados}

En la Tabla 10 se establece los resultados obtenidos sobre los factores sociales:

TABLA 10

Factores sociales

\begin{tabular}{|l|l|l|l|}
\hline Dimensiones & Deseado & Sí & No \\
\hline \multirow{4}{*}{$\begin{array}{l}\text { Factores } \\
\text { Sociales }\end{array}$} & 1.1. Ambiente familiar & 96,5 & 3,5 \\
\cline { 2 - 4 } & $\begin{array}{l}\text { 1.2. Estabilidad } \\
\text { económica }\end{array}$ & 72,4 & 27,6 \\
\cline { 2 - 4 } & 1.3. Estrato social & 74,1 & 25,9 \\
\hline
\end{tabular}

Fuente: Elaboración propia con base en la Matriz de Operacionalización de Variables. 


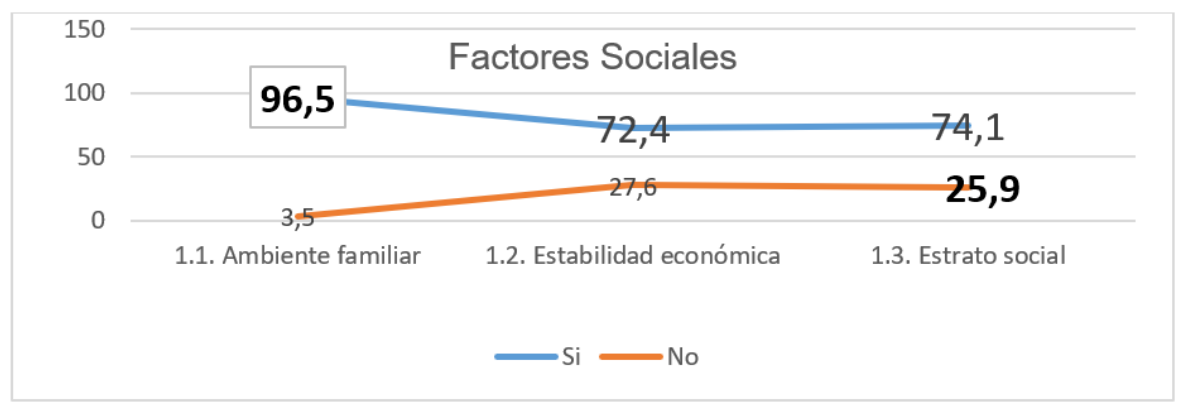

GRÁFICO 1

Factores sociales

Fuente: Elaboración propia con base en encuestas a estudiantes de FCQ

Interpretación: Con base en el Gráfico 1: Factores sociales. Los resultados obtenidos son: el 96,5\% alude que el ambiente familiar si influye en un bajo rendimiento. Así, la influencia del padre, madre o adulto responsable repercute significativamente en la vida académica esto lo menciona Garbanzo (2007). Diferentes investigaciones en la Revista de Educación mencionan que la violencia familiar es un factor asociado al fracaso académico. De esta manera se logra destacar el ambiente familiar como un indicador social con los valores más altos en el proceso académico del estudiantado que puede repercutir en este.

La Tabla 11 se hace referencia a los factores personales que propician un bajo rendimiento:

TABLA 11

Factores personales

\begin{tabular}{|l|l|l|l|}
\hline Dimensiones & Ítems & Sí & No \\
\hline \multirow{4}{*}{$\begin{array}{c}\text { Factores } \\
\text { personales }\end{array}$} & 2.1. Jornadas extensas & 81,2 & 18,8 \\
\cline { 2 - 4 } & $\begin{array}{l}\text { 2.2. Retroalimentación de } \\
\text { información }\end{array}$ & 84,7 & 15,3 \\
\cline { 2 - 4 } & 2.3. Organización de tiempo & 84,7 & 15,3 \\
\cline { 2 - 4 } & 2.4. Carencia de hábitos & 69,4 & 30,6 \\
\cline { 2 - 4 } & 2.5. Técnicas de estudio & 70,6 & 29,4 \\
\cline { 2 - 4 } & 3.6. Aprendizaje autónomo & 76,5 & 23,5 \\
\cline { 2 - 4 } & 3.7. Salud integral & 92,9 & 7,1 \\
\cline { 2 - 4 } & 3.8. Per fil vocacional & 76,5 & 23,5 \\
\cline { 2 - 4 } & 3.9. Estado civil & 88,2 & 11,8 \\
\hline
\end{tabular}

Fuente: Elaboración propia con base en encuestas a estudiantes de la Facultad de Ciencias Químicas

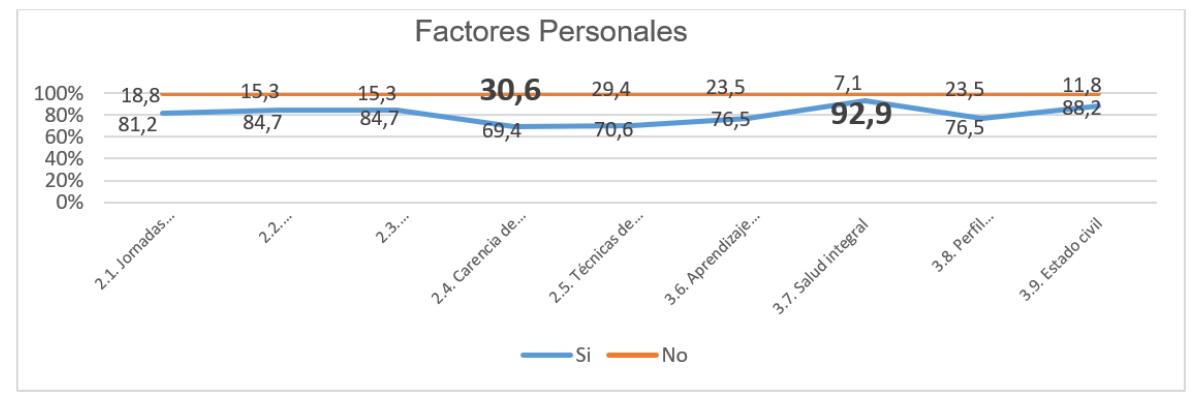

GRÁFICO 2

Factores Personales

Fuente: Elaboración propio de las autoras: Encuestas a estudiantes de FCQ

Interpretación: Con base en el Gráfico 2: Factores personales. Los resultados obtenidos son: El 92,9\% afirma que las personas que gozan de una salud integral, es decir física y psicológica, están en condiciones para 
lograr un aprendizaje significativo, según (Garbanzo ,2007). El estado de ánimo y el aspecto físico influyen mucho en el desempeño del estudiantado, pues, si hay carencias de uno de estos aspectos, la posibilidad de perder una materia aumenta de forma considerable.

Por otra parte, el estado civil, con un valor de $88,2 \%$, también influye considerablemente, esto lo mencionan Bañuelos, et al., (2013), quienes destacan que el estudiantado que cumple con un rol de cabeza de familia les impide dedicar el tiempo necesario a sus estudios, pues comparten varias responsabilidades simultáneamente. Así se puede constatar que estos dos indicadores afectan notablemente en el desarrollo personal y académico del estudiantado.

En la Tabla 12 se presentan los factores institucionales influyentes en el rendimiento académico:

TABLA 12

Factores institucionales

\begin{tabular}{|l|l|l|l|}
\hline Dimensiones & Deseado & Sí & No \\
\hline \multirow{4}{*}{$\begin{array}{c}\text { Factores } \\
\text { institucionales }\end{array}$} & 3.1. Sistema de evaluación & 70,4 & 29,6 \\
\cline { 2 - 4 } & $\begin{array}{l}\text { 3.2. Responsabilidad que exige } \\
\text { los niveles superiores }\end{array}$ & 80,2 & 19,8 \\
\cline { 2 - 4 } & 3.3. Preparación docente & 89,4 & 30,6 \\
\cline { 2 - 5 } & 3.4. Organización institucional & 75,6 & 24,4 \\
\cline { 2 - 4 } & 3.5. Infraestructura & 90,4 & 9,6 \\
\hline
\end{tabular}

Fuente: Elaboración propia con base en encuestas a estudiantes de FCQ

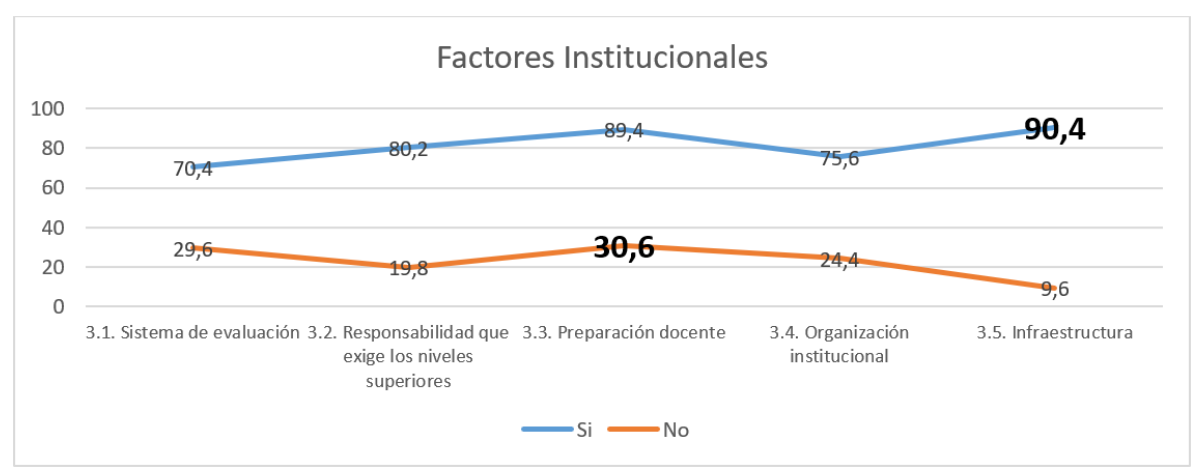

GRÁFICO 3

Factores institucionales

Fuente: Elaboración propia con base en encuestas a estudiantes de FCQ

Interpretación: Con base en el Gráfico 3: Factores institucionales los resultados obtenidos son: el 90,4\% afirma que la infraestructura puede ser un indicador para no lograr un conocimiento óptimo. Según Poblete et al., (2013) la gestión administrativa o mejoramiento de la infraestructura escolar tiende a fomentar un buen ambiente estudiantil, tratando de mejorar el lugar de trabajo y mejorar el conocimiento del estudiantado.

Un $89,4 \%$ afirma que la preparación del cuerpo docente es de suma importancia para impartir conocimientos que permitan el desarrollo y comprensión del estudiantado. Según Montes y Suárez (2016), la formación integra es uno de los factores esenciales para el perfeccionamiento del perfil profesional del cuerpo docente universitario, y es básica para lograr estudiantes con conocimientos sólidos y universidades con calidad educativa.

En la Tabla 13, se presentan los factores pedagógicos asociados al rendimiento estudiantil: 
TABLA 13

Factores pedagógicos

\begin{tabular}{|l|l|l|l|}
\hline Dimensiones & Deseado & Si & No \\
\hline \multirow{5}{*}{$\begin{array}{c}\text { Factores } \\
\text { pedagógicos }\end{array}$} & 4.1. Estrategias didácticas & 75,7 & 24,3 \\
\cline { 2 - 4 } & 4.2. Aprendizaje eficiente & 82,3 & 17,7 \\
\cline { 2 - 4 } & 4.3. Tutorias & 45,2 & 54,8 \\
\cline { 2 - 4 } & $\begin{array}{l}\text { 4.4. Carga horaria } \\
\text { 4.5. Relación alumnado- } \\
\text { profesorado }\end{array}$ & 88,2 & 11,8 \\
\cline { 2 - 4 } & $\begin{array}{l}\text { 4.6. Perfil profesional del grupo } \\
\text { docente }\end{array}$ & 76,1 & 25,9 \\
\hline
\end{tabular}

Fuente: Elaboración propia con base en encuestas a estudiantes de FCQ

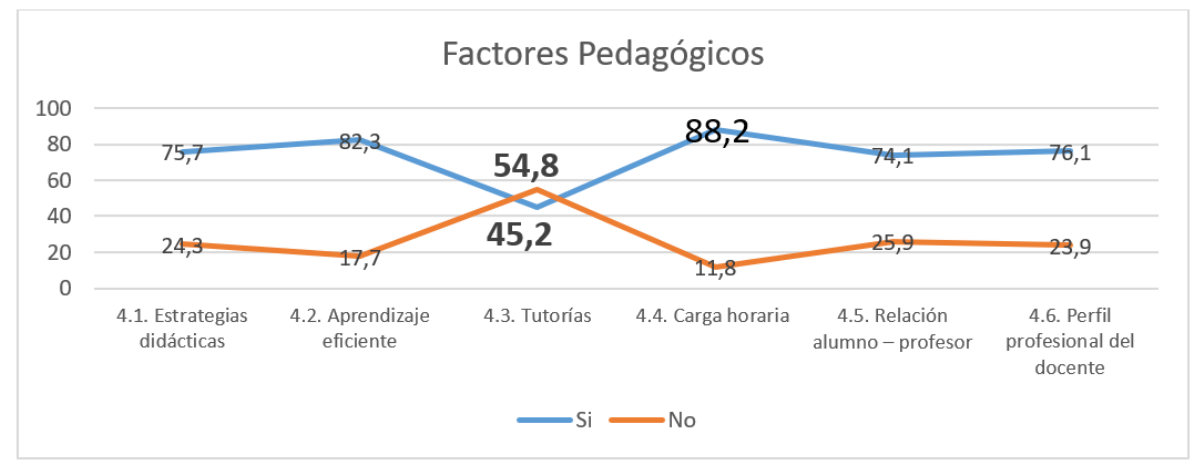

GRÁFICO 4

Factores pedagógicos

Fuente: Elaboración propia con base en encuestas a estudiantes de FCQ

Interpretación: Con base en el Gráfico 4: Factores pedagógicos. Los resultados son: un 88,2\% afirma que la carga horaria impide dedicar el tiempo necesario para estudiar. Fernández (2011) afirma que la carga horaria y la extensa jornada de estudio tienen un impacto negativo en el área académica motivo por el cual el estudiantado presentan un bajo rendimiento académico, siendo este indicador el más significativo dentro del estudio.

Por otro lado, el indicador, aprendizaje eficiente, con el 82,3\%, indica que este sí influye negativamente en el desarrollo académico, ya que hoy en día el alumnado debe investigar e intercambiar información para enriquecer sus conocimientos y así obtener un aprendizaje eficiente, así lo sugiere (Jiménez, 2014)

\section{ANÁLISIS Y DISCUSIÓN}

Se han encontrado algunas variables y factores que se establecen como causantes para que el estudiantado abogue por una tercera matrícula, estas se relacionan con el bajo rendimiento que presenta la muestra estudiada de 126 estudiantes de tercera matrícula. De manera similar, en cuanto al factor educativo, las y los jóvenes encuestados muestran impacto negativo en la calidad de asimilación del aprendizaje, ya que una incorrecta metodología en el proceso de enseñanza, como la carga excesiva de trabajos o un aprendizaje mecánico, no permite el desarrollo de las habilidades del alumnado, lo que genera así un bajo rendimiento académico ocasionado por la forma incorrecta de asimilar contenidos.

Se puede observar en las Tablas 11 y 13 en los ítems 4.4 (Carga horaria) y 2.3 (organización de tiempo); se establece que el tiempo del estudiantado, al ser muy reducido, limita que organicen su tiempo de manera 
adecuada y necesaria, lo que les impide trabajar de manera autónoma para mejorar su rendimiento académico como lo aseveran Bañuelos, et al., (2013).

En los resultados 1.1 (Ambiente familiar) y 2.6 (Aprendizaje autónoma) manifiesta Flores (2016), que el bienestar psicológico y físico del alumnado varía según los problemas que se suscitan dentro y fuera del área académica, pues desconcentran a tal punto que impide a jóvenes universitarios enfocarse totalmente en sus estudios lo cual, a largo plazo, perjudicará en su rendimiento y este a su vez traerá problemas en el entorno, así también alude que el alumnado que estudia de forma autónoma debe poseer técnicas de estudio, pues esto permitirá que el conocimiento pueda llegar a un aprendizaje significativo de manera más sencilla para lograr un proceso adecuado de enseñanza-aprendizaje, pues señala que si lo hace de manera mecánica, el conocimiento no solo será temporal sino que también escaso, razón por la cual un 70,6\% del sector estudiantil manifestaron que al hacer uso de las diferentes técnicas como factor personal 2.5 (técnicas de estudio) con el fin de mejorar su rendimiento son importantes para llegar a un correcto aprendizaje.

Se puede observar en las Tablas 10 y 13 en los ítems 4.2 (Aprendizaje eficiente ), 4.3 (Tutorías) 4.1 (Estrategias didácticas), 4.5 (Relación alumnado-profesorado) y 2.7 (Salud integral ) que se establece que una preparación escolar que brinde bases académicas sólidas permitirá que el estudiantado pueda desenvolverse de mejor manera en los siguientes niveles de educación superior, esto, depende de la institución educativa y a su vez de la preparación por cuenta propia del estudiantado, la cual al ser acompañada de una correcta metodología de estudios por parte del grupo docente permitirá suministrar información necesaria. Sin embargo, los problemas cognitivos acompañados de un imperfecto programa académico del establecimiento y la enseñanza tradicional, impiden que el alumnado logre desarrollar sus capacidades dentro del área académica lo que en un futuro generará problemas a medida que el nivel de educación va aumentando.

Se puede observar que en la Tabla 10 en los ítems 2.2 (Retroalimentación de información) se establece que la ausencia de conocimientos base conllevará a un fracaso académico si no se llega a trabajar en ellos (Garbanzo, 2007). Así lo muestran los resultados obtenidos, donde se puede apreciar que un número considerable de estudiantes reflexiona la idea de que las bases bien estructuradas son el pilar fundamental para dar paso a la generación de nuevos conocimientos en cuanto a sus carreras.

En la Tabla 10 en los ítems 2.8 (Perfil vocacional) se menciona que la mayoría de estudiantes que inician su carrera universitaria no conocen en su totalidad acerca de esta, lo que constituye un obstáculo en el individuo para su formación académica, lo cual se manifiesta en deficiencias frente a la asignatura lo que genera un bajo rendimiento y en el peor de los casos se recae en una tercera matrícula (Universidad de los Andes, 2007). Bajo estas condiciones, en las que el estudiantado no se encuentra afín a la carrera universitaria se llegan a generar hasta el abandono académico por un retiro forzado o voluntario, a su vez también existe un número reducido de estudiantes que afirman que han escogido una carrera universitaria con base en sus habilidades, es decir, por vocación. Así se lo puede apreciar en los resultados alcanzados, donde gran parte del estudiantado de la Facultad de Ciencias Químicas se muestran afines a su carrera, lo que se entiende estadísticamente que estudian su carrera con base en la vocación.

Se puede observar que en las Tablas 11 y 13 en los ítems 4.6 (Perfil profesional del y la docente), 2.5 (Técnicas de estudio), 2.4 (Carencia de hábitos) y 3.2 (Responsabilidad de niveles superiores) se alude que la calidad de enseñanza que imparten al grupo docente al alumnado debe girar en torno a garantizar, ante la institución educativa y por ende a la sociedad, que el proceso didáctico se ejecute con las características deseadas de manera tal que se logren las metas propuestas. Todo dentro de un proceso que busque la mejora constante, que sea una función eminente de carácter social.

\section{Conclusiones}

El estudiantado encuestado de tercera matrícula durante los periodos 2017-2018 y 2018-2018 perteneciente a la Facultad de Ciencias Químicas de la Universidad Central del Ecuador se determinó que los factores 
que inciden en su fracaso académico son muy diversos, entre los que se encuentran los procesos cognitivos identificados en los problemas de atención, concentración y comprensión.

Los factores personales ligados al aprendizaje y la baja motivación para asistir a clases y efectuar sus tareas por falta de conocimiento y dominio de la materia; los componentes inherentes a la personalidad, tales como la falta de confianza, la baja tolerancia a la frustración y síntomas de depresión y ansiedad, los cuales fueron estudiados en esta investigación, afectan el rendimiento óptimo del estudiantado. Así también factores educativos, entre los que se encuentran incorrectas técnicas de estudio y la mala distribución del tiempo, lo que se concluye en que tantos factores sociales, personales, institucionales y pedagógicos conllevan a que el estudiantado no apruebe las asignaturas y deba solicitar no solo una segunda sino hasta una tercera matrícula.

En los resultados obtenidos se determinó que los problemas en la familia impide al sector estudiantil dedicarse a tiempo completo, lo cual repercute en un bajo rendimiento, así también los problemas de salud que generan inconvenientes en el desarrollo de las actividades educativas y esto a su vez provoca que los factores académicos como la carga horaria que deben cumplir no lo puedan efectuar, dado que no pueden dedicarse a tiempo completo a sus estudios y otras actividades que deban cumplir, se constituyen en un distractor para el desarrollo de su aprendizaje.

La presente investigación permitió la descripción de los factores que generan un bajo rendimiento en la población estudiada, es decir, el estudiantado que ha solicitado una tercera matrícula durante los periodos 2017-2018 y 2018-2018 dentro de la Facultad de Ciencias Químicas la cual ha sido resultado de un estudio investigativo.

Se demostraron los diversos factores que afectan a la población estudiada con el fin de determinar los factores que influyeron en el estudiantado durante este proceso educativo dentro de la Facultad de Ciencias Químicas, en los períodos académicos estudiados.

Se especificó cuáles son las normativas aplicables, con base en la reglamentación de la Universidad Central del Ecuador dentro del sistema académico $S I I U$ para ejecutar el proceso de solicitud de una tercera oportunidad de tomar una asignatura.

Se logró determinar la cantidad del alumnado que han solicitado y cursado una tercera matrícula durante los periodos semestrales de septiembre 2017- marzo 2018 y abril 2018- agosto 2018 lo que dio como resultado una población total de 343 estudiantes en la Facultad de Ciencias Químicas.

\section{Recomendaciones}

El sistema educativo implica tener una visión clara y objetiva de los requerimientos del mundo en el que vivimos, lo que trae consigo la necesidad de reflexionar acerca de los principios generales que rige una metodología adecuada para la enseñanza del estudiantado. Todo el cuerpo docente que desempeña su rol profesional dentro de la Universidad Central del Ecuador está en la obligación de desarrollar un proceso exhaustivo de análisis que les permita una revisión de la calidad de conocimientos y así también su actitud personal dentro del entorno laboral.

Una docencia adecuada debe trasformar las formas de evaluar, para que varíe la manera de prepararse con el fin de estimular la formación y mejorar las estrategias con las que el conocimiento llega al alumnado, así también procurar programar evaluaciones que estimulen las diferentes habilidades que enriquezcan de manera integral a el estudiantado que se les ha encomendado.

Una recomendación a directoras y directores de carrera de la Facultad de Ciencias Químicas es generar procesos de formación que le permitan al cuerpo docente de la facultad cambiar los paradigmas de enseñanza aplicados en las diversas asignaturas que forman parte de la malla curricular, a efectos de estas se constituyan como una real opción en el desarrollo cognoscitivo y productivo del estudiantado.

Es recomendable que el estudiantado perteneciente a la Facultad de Ciencias Químicas muestre interés ante la asignatura en peligro, con el fin de que el grupo docente pueda reforzar estrategias para llegar con la 
información y estrategias didácticas oportunas al alumnado, para que este sea promovido al siguiente nivel con suficientes bases de los contenidos estudiados.

\section{BiBLIOgRAFÍA}

Bañuelos, A., Guerrero, A., y Sánchez, J.L. (2013) Perfiles asociados al abandono escolar: Un caso del sistema universitario abierto de la UNAM. Tercera conferencia latinoamericana sobre el abandono en la educación superior. Conferencia llevada a cabo en el congreso de la Universidad Nacional Autónoma de México.

Cardozo, O. C. E., Tiga L. D. C., Fajardo P. M. T., y Vargas H. D. C. (2016). Pérdida de asignaturas en los estudiantes de enfermería: aspectos económicos, familiares y psicosociales. Revista de La Universidad Industrial de Santander. Salud, 48(4), 486-495. doi: https://doi.org/10.18273/revsal.v48n4-2016007

Corral, V. y Díaz, X. (2009). Factores asociados a la reprobación de los estudiantes de la Universidad de Sonora. (Tesis de maestria).Universidad de Sonora. Hermosillo, México.

Dunlosky, J. (2018). Educación 3.0. Recuperado de https://bit.ly/2Ak7J82

Fernández, Y. (2011). Variables académicas que influyen en el rendimiento académico en los estudiantes universitarios. Investigación Educativa, 15 (27), 165-179. Recuperado de https://bit.ly/2BCWpV5

Flores, J. (2016). Factores relacionados a la repitencia en las asignaturas de Química en estudiantes del primer semestre en las carreras de Bioquímica y Químico Farmacéutica de la UAJMS2. Ventana Cientifica, 11(7), 10 - 21. Recuperado de http://www.uajms.edu.bo/revistas/wp-content/uploads/2017/09/Ventana-Cientifica-Nro-11 .pdf

Garbanzo, G. M. (2007). Factores asociados al rendimiento académico en estudiantes universitarios, una reflexión desde la calidad de la educación superior pública. Revista Educación. 31(1), 43-63. Recuperado de https://bit.l y/2BGHGIC

Jiménez, M. (2014). Lo que necesita un buen estudiante. Vida Cientifica Boletín Cientifico De La Escuela Preparatoria No. 4,2(4). Recuperado de https://n9.cl/1j57

Instituto Nacional de Estadísticas y Censos (INEC). (2011). Encuesta de estratificación de nivel socioeconómico. Recuperado de https://bit.ly/2xSD8xo

Machorro, M., y Valdez, V. (2016). Universidad Autónoma del Estado de Hidalgo. Recuperado de https://www.uaeh .edu.mx/scige/boletin/prepa4/n4/e19.html

Montes, D. A. y Suárez, C. I. (2016). La formación docente universitaria: claves formativas de universidades españolas. Revista Electrónica de Investigación Educativa, 18(3), 51-64. Recuperado de http://redie.uabc.mx/redie/article /view/996

Monzón, C. (2015). Factores sociales que influyen en el rendimiento académico de los estudiantes del primer año semestre 014-II de la Escuela Profesional de Odontología de la UNA PUNA (Tesis de grado).Universidad Nacional del Altiplano, Perú. Recuperado de https://bit.ly/3bpLni2

Pérez V. M. V., Valenzuela, M., Díaz M. A., González, J. A. y Núñez, J. C. (2013). Dificultades de aprendizaje en estudiantes universitarios de primer año. Atenea (Concepción), (508), 135-150. doi: https://doi.org/10.4067/ s0718-04622013000200010

Poblete, X., Sepúlveda, P., Orellana, V. y Abarca, G. (2013). Situación Educativa De América Latina y El Caribe para todos al 2015. Chile: Orealc/Unesco. Recuperado de http://works.bepress.com/cgi/viewcontent.cgi?article=1 009\&context $=$ cesar_guadalupe

Quica, N. Y. (2016). Deserción universitaria en Universidad Surcolombiana (Neiva). Recuperado de https://reposito ry.unad.edu.co/handle/10596/6277

Redacción El Tiempo. (10 de agosto de 2012). La tercera matrícula tiene reglas. El Tiempo, diario de Cuenca, pp. 1-1. Recuperado de https://www.eltiempo.com.ec/noticias/cuenca/2/la-tercera-matricula-tiene-reglas

Sampieri, R., Fernández, C., Baptista, P. y Pérez, C. (1991). Metodología de la investigación . México: MG GRAW HILL. 
Tejedor, F., y García, A. (2007). Causas del bajo rendimiento del estudiante universitario. Revista de educación, 342, 343-473. Recuperado de https://dialnet.unirioja.es/servlet/articulo?codigo $=2254218$

Torres, J., Acevedo, D. y Gallo, L. (2015). Causas y consecuencias de la deserción y repitencia escolar: una visión general en el contexto latinoamericano. Cultura educación y sociedad, 6 (2). 157-187. Recuperado de https:// bit.ly/37WpabB.

Universidad Central del Ecuador. (2018). Sistema Integral de Información Universitaria. Preguntas frecuentes Tercera Matricula. Universidad Central del Ecuador. Recuperado de https://aka-cdn.uce.edu.ec/ares/tmp/SIIU/Terce ras.pdf

Universidad de los Andes. (2007). Investigación sobre deserción en las instituciones de educación superior en Colombia. Ecuador: Universidad de los Andes. Recuperado de https://studylib.es/doc/7619308/informe-t\%C3\%A9cnic o-del-cede---ministerio-de-educaci\%C3\%B3n

Zárate, R., y Mantilla, E. (2014). La deserción estudiantil UIS, una mirada desde la responsabilidad social universitaria. Zona Próxima, (21), 121-134.Recuperado de https://www.redalyc.org/articulo.oa?id=853/85332835010

\section{Anexo 1}

\section{Solicitud de tercera matrícula}

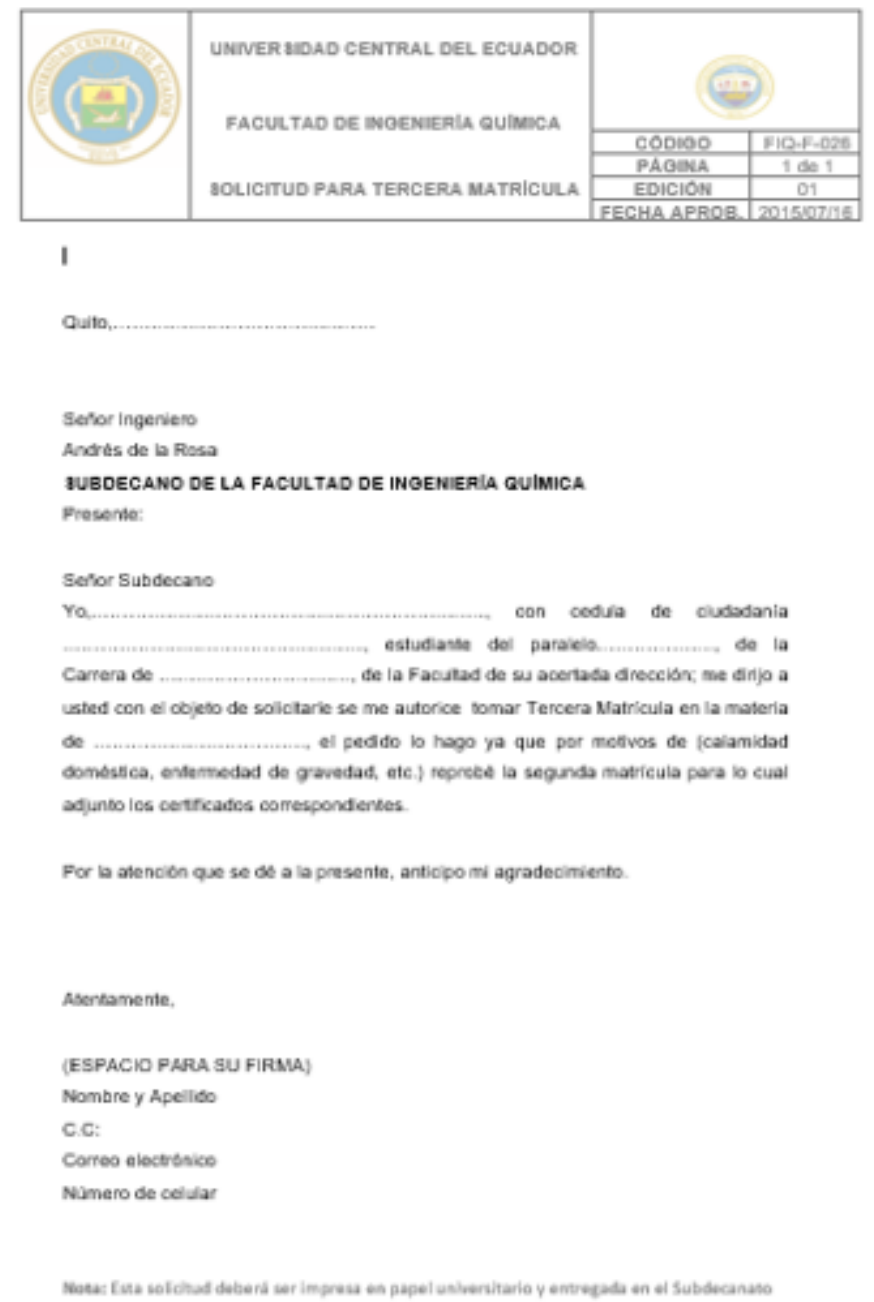

ANEXO 1

Fuente: Universidad Central del Ecuador 
Lizbeth Alexandra Catota Caiza, et al. Estudio de los factores que influyen en estudiantes con ter...

\section{Anexo 2}

\section{Operacionalización de las variables}

ANEXO 2

\begin{tabular}{|c|c|c|c|}
\hline $\begin{array}{l}\text { VARIABLES } \\
\end{array}$ & DIMENSIONES & INDICADORES & ITEMS \\
\hline \multirow{4}{*}{$\begin{array}{l}\text { Factores } \\
\text { que influyen } \\
\text { en una } \\
\text { tercera } \\
\text { matricula La } \\
\text { cantidad de } \\
\text { estudiantes } \\
\text { que inciden } \\
\text { para una } \\
\text { tercera } \\
\text { matricula. }\end{array}$} & Sociales & $\begin{array}{l}\text { Ambiente Familiar } \\
\text { Estabilidad Económica } \\
\text { Estrato Social }\end{array}$ & $\begin{array}{l}\text { 1.1 ¿Cree usted que los } \\
\text { diferentes problemas en el } \\
\text { hogar desconcentran y } \\
\text { desmotivan al } \\
\text { estudiantado? } 1.2 \text { ¿Tiene } \\
\text { los recursos necesarios } \\
\text { para solventar sus } \\
\text { estudios? } 1.3 \text { ¿Cuenta con } \\
\text { el apoyo económico para } \\
\text { sus estudios } \\
\text { universitarios? }\end{array}$ \\
\hline & Personales & $\begin{array}{l}\text { Jornadas extensas. } \\
\text { Retroalimentación. } \\
\text { Organización de } \\
\text { tiempo. Carencia de } \\
\text { hábitos. Técnica de } \\
\text { estudios. } \\
\text { Aprendizaje } \\
\text { Autónomo. Salud } \\
\text { Integral. Perfil } \\
\text { Vocacional. Madres o } \\
\text { padres de familia }\end{array}$ & 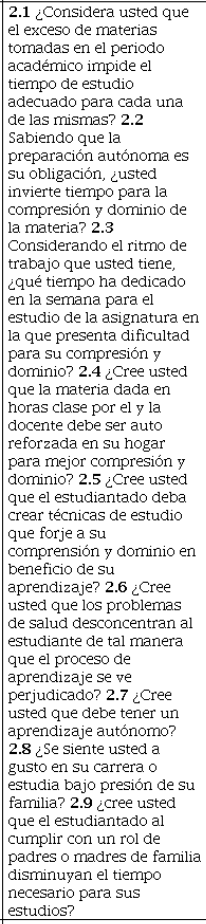 \\
\hline & Institucionales & 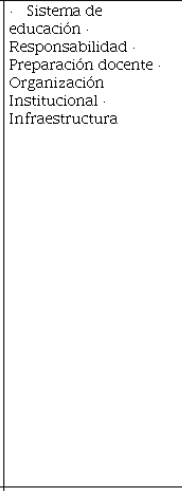 & 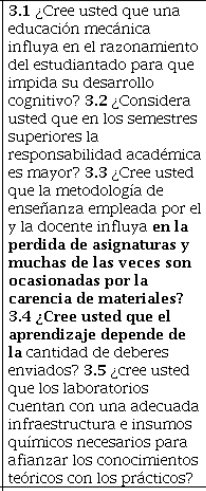 \\
\hline & Pedagógicos & $\begin{array}{l}\text { Estrategias } \\
\text { Didácticas. } \\
\text { Aprendizaje Eficiente } \\
\text { Tutorias. Carga } \\
\text { Horaria. Relación } \\
\text { alumno-profesor. } \\
\text { Perfil Profesional de } \\
\text { docente }\end{array}$ & 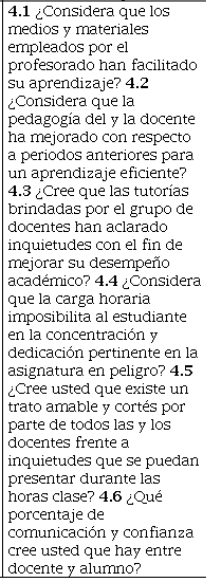 \\
\hline
\end{tabular}


Revista EduCACión, 2020, vol. 44, NÚM. 2, Julio-Diciembre, ISSN: 0379-7082 2215-2644,

Fuente: Elaboración propia 